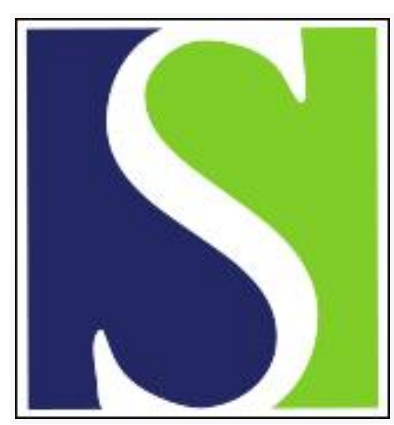

Scand J Work Environ Health 1998;24(1):54-61

https://doi.org/10.5271/sjweh.278

Issue date: Feb 1998

Relationship of job strain and iso-strain to health status in a cohort of women in the United States

by Amick III BC, Kawachi I, Coakley EH, Lerner D, Levine S, Colditz GA

The following articles refer to this text: $2004 ; 30(2): 85-128$;

2004;30(6):477-485; 2006;32(4):285-293; 2006;32(6):473-481; SJWEH Supplements 2008;(6):98-110; 2008;34(4):288-296;

2013;39(3):241-258

Key terms: gender; job control; job demand; mental health; physical health; social support

This article in PubMed: www.ncbi.nlm.nih.gov/pubmed/9562401 


\title{
Relationship of job strain and iso-strain to health status in a cohort of women in the United States
}

\author{
by Benjamin C Amick III, PhD, ${ }^{1,2}$ Ichiro Kawachi, MD, ${ }^{2,3}$ Eugenie H Coakley, MA, ${ }^{3,4,5}$ \\ Debra Lerner, PhD, ${ }^{1}$ Sol Levine, PhD, ${ }^{1,2}$ Graham A Colditz, MD ${ }^{3,5}$
}

Amick BC III, Kawachi I, Coakley EH, Lerner D, Levine S, Colditz GA. Relationship of job strain and iso-strain to health status in a cohort of women in the United States. Scand J Work Environ Health 1998:24(1):54—61.

\begin{abstract}
Objective This study examined the relationships of job strain and iso-strain psychosocial work-environment exposures to health status in a cohort of working women in the United States.

Methods In a cross-sectional survey, 33689 women responded to the Karasek job content and the MOS SF36 health status questionnaires. The psychosocial work-environment exposures were characterized using the job strain and iso-strain frameworks. Health status was assessed with the following 6 scales: physical functioning, vitality, freedom from pain, mental health, role limitations due to physical health, and role limitations due to emotional health.

Results When compared with active work, high-strain work (high job demands and low job control) was associated with lower vitality, mental health, higher pain, and increased risks of both physical and emotional role limitations. Iso-strain work (high strain and low work-related social support) increased the risks further. Job insecurity was also associated with lower health status.

Conclusions The analyses supported the hypothesis that the psychosocial work environment is an important determinant of health status among working women. The findings suggest that incorporating social conditions at work into the measurement of psychosocial work-environment exposure improves the identification of highrisk work arrangements.
\end{abstract}

Key terms gender, job control, job demands, mental health, physical health, social support.

Work high in psychological demands and low in level of control has been associated with a variety of deleterious health consequences $(1,2)$. These elements have been combined into a 2-dimensional job strain model characterizing psychosocial work exposure (figure 1). An extension of this model, called the iso-strain model, posits that the most hazardous work occurs when high job strain is combined with low levels of supportive social interaction at work (figure 2) (3-7). Tests of these models have been carried out more often in studies of men than in studies of women, and therefore some authors question their applicability to women (8). The few prospective studies of working women found that high strain at work increased the risk of cardiovascular disease in the United States (9) and Sweden (10) and increased the risk of stroke (10), problem drinking (10), and elevated blood pressure $(11,12)$. Less is known about the impact of iso-strain on women's health because prospective evidence is only available for men (4).

The public health significance of these psychosocial work exposure models lies in their capacity to identify hazardous ( $\mathrm{eg}$, high strain and iso-strain), as well as health-enhancing (eg, active) work settings. To date, research has focused on high-strain work as an occupational health hazard, while generally overlooking the potential health promoting effects of some work arrangements (13). This perspective is a consequence of using measures of morbidity and mortality and not measures capturing the spectrum of a person's health status. In the present study, a multidimensional health status mea-

1 The Health Institute, New England Medical Center, Boston, Massachusetts, United States.

2 Department of Health and Social Behavior, Harvard School of Public Health, Boston, Massachusetts, United States.

3 Channing Laboratory, Harvard Medical School and Brigham and Women's Hospital, Boston, Massachusetts, United States.

4 Department of Nutrition, Harvard School of Public Health, Boston, Massachusetts, United States.

5 Department of Epidemiology, Harvard School of Public Health, Boston, Massachusetts, United States.

Address for correspondence: Dr Benjamin C Amick III, The Health Institute, New England Medical Center, 750 Washington Street, Box 345, Boston MA 02111, USA. [e-mail: benjamin.amick@es.nemc.org]

Reprint requests to: Dr I Kawachi, Channing Laboratory, 181 Longwood Avenue, Boston MA 02115, USA. 


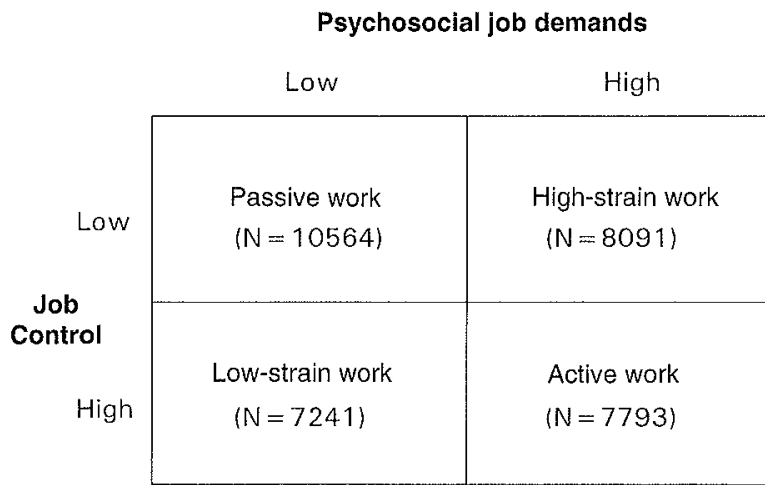

Figure 1. Two-dimensional model for job strain.

sure was used to examine the relationships of all categories of job strain and iso-strain work to health status in a cohort of working women in the United States. In addition, by controlling for biomedical factors and health behavior predictive of health status, this research builds on an earlier study (14) that demonstrated an association between job strain and health status.

\section{Subjects and methods}

\section{Nurses' health study cohort}

The nurses' health study cohort was established in 1976 , when 121700 female registered nurses between the ages of 30 and 55 years completed a postal questionnaire about risk factors for cancer and cardiovascular disease, including current and past smoking habits and personal history of hypertension, diabetes mellitus, hypercholesterolemia, and other diseases. Since 1976, follow-up questionnaires have been sent every 2 years to the entire cohort to update information on risk factors and the occurrence of major illnesses. All reports of major illnesses, such as cancer, coronary heart disease (CHD) and stroke, are independently confirmed by physician review of medical records following preestablished diagnostic criteria (15). Altogether 5 mailings, including certified mail, are sent out during each questionnaire cycle. A follow-up rate of over $90 \%$ has been maintained throughout the 20-year period of the study.

The 1992 questionnaire cycle included items from the Karasek job content questionnaire (16) and the SF-36 health status measure (17). Altogether 75434 women returned the first mailing (65.2\% response rate). Although 104064 women eventually responded to the 1992 questionnaire $(90.0 \%$ cumulative response rate), the job content questionnaire and the SF-36 instruments were only included in the first cycle to minimize respondent burden. Women who did not complete the job content questionnaire and SF-36 were somewhat older, heavier, more sedentary, and less likely to have graduate training than nurses who completed the full questionnaire. However, the differences between the 2 groups were small.

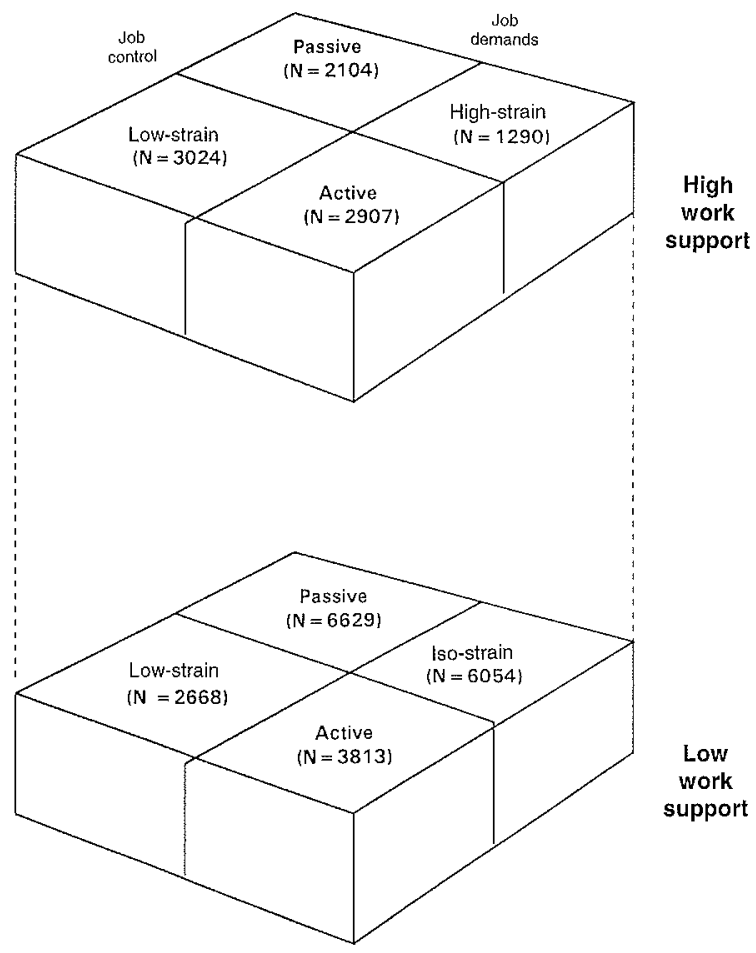

Figure 2. Extension of the two-dimensional model for job strain.

To minimize the potentially confounding effect of major illness on the relationship between psychosocial work exposure and health status, we excluded 12701 women who had a clinically confirmed history of CHD (defined as myocardial infarction or angina pectoris), cancer, or stroke through 1992. We also excluded 24056 women who were retired, living in a nursing home, or were otherwise not in the paid work force in 1992. Finally, we excluded 4988 women with missing information on the exposure, outcome, or covariate measures. Our final study population therefore was 33689 women engaged in paid work who were free of diagnosed $\mathrm{CHD}$, stroke, and cancer.

\section{Measurement of exposure}

Job demands and job control were measured with the job content questionnaire (16). The job demands scale is the sum of 5 items that measure the level of psychological demands at work (excessive work, conflicting demands, insufficient time to do work, fast work pace, working hard). The job control scale is the sum of 2 subscales: skill discretion as measured by 6 items (continual learning of new things on the job, ability to develop skills, job requiring skill, task variety, work not repetitious, job requiring creativity) and decision authority measured by 3 items (freedom to make decisions, choice about how to perform work, having a lot of say on the job). For each demand and control item, the respondents could choose from 1 of 4 responses varying from strongly disagree to strongly agree. A comparison found no differences for job demands and job control medians in this cohort of 
primarily nurses with national data comprised of many occupations (14).

To measure job strain, the job demands and job control scales were converted to dichotomous measures by splitting them on the median. A cross-classification of these 2 measures produces the $2 \times 2$ matrix shown in figure 1 , which defines 4 exposure categories (14). Persons on the median were classified as having less severe exposure (low demands or high control), resulting in a conservative exposure assessment. Four variables $(1=$ yes, $0=$ no) indicating the type of work - high strain, low strain, passive, and active - were created.

For the measurement of iso-strain, first, a work-related support scale was constructed by summing 2 scales: support from co-workers (they take a personal interest in me, are friendly, helpful in getting the job done, and competent in doing work) and support from supervisors (concerned about the welfare of those under her, pays attention, helpful in getting the job done, successful in getting people to work together). The response choices for each item varied on a 4-point scale from strongly disagree to strongly agree (16). A "not applicable" response was added to the supervisor support questions. Next, work-related support was split on the median with persons above the median classified as receiving high support. Finally, work-related support was cross-classified with job strain to create 8 exposure groups (figure 2) (3). Eight variables $(1=$ yes, $0=$ no) indicating the 8 exposure groups were created. It should be noted that the population sizes are different for our job strain and iso-strain models because we excluded 5200 women who checked "not applicable" to the questions about support received from their supervisors from the iso-strain analysis. Exclusion of these women from multivariate job strain analyses did not change the results.

\section{Measurement of health status}

Health status was measured using a modified version of the medical outcomes study SF-36 health survey - a short, comprehensive measure of 8 dimensions of general health (18). These scales were derived from general health status scales designed to represent 2 major dimensions of health: physical and mental (19-21). Detailed descriptions of the conceptual background, development and psychometric validity, and the reliability of the SF-36 can be found elsewhere $(17,18,20,22,23)$. The SF-36 was modified in 2 ways. The item order was changed, and 1 item assessing general health perception was omitted. We included 6 of the 8 multiitem scales. A 2-item social functioning scale was excluded because of the use of social support as a predictor of health status in our iso-strain models, and the 1992 questionnaire did not include all items necessary to construct the general health perceptions scale. The 6 remaining scales measured both the physical and mental components of health status. Physical functioning (10 items) measured the ability to perform a variety of daily activities and tasks which require physical effort, such as climbing stairs. Role limitations due to physical problems ( 4 items) assessed the limitations a person has in performing work and other usual activities as a result of physical health problems. Freedom from bodily pain (2 items) assessed self-reported bodily pain and discomfort. Vitality (4 items) measured the perceived level of energy and fatigue. Role limitations due to emotional problems ( 3 items) measured the limitations a person has performing work and other usual activities as a result of emotional problems. Finally, mental health (5 items) assessed both positive and negative emotional states. The response choices varied from yes or no (eg, role limitation scales) to 6-point likert-type responses (eg, mental health, vitality). All the scale scores were standardized to vary between 0 and 100 to facilitate comparability across scales and with other studies (17). A higher score indicated better health, well-being, or functioning. For the respondent to be included in the analysis, data had to be available on at least half of the items within each health status scale. Where responses were missing for items on any scale, we substituted a respondent's average response to all other items on the scale (17). Because of the extreme skewness of the role limitation scales (mean and median 100), both were recoded with 1 indicating "any limitation" (scores of $<100$ ) and 0 as "no limitation" (score of 100).

\section{Measurement of covariates}

Several covariates were identified as confounders of the relationship between job strain and health status. A set of variables indicated ( $1=$ yes, $0=$ no) whether or not a respondent had a chronic illness (diabetes, high blood pressure, hypercholesterolemia, osteoarthritis, rheumatoid arthritis), never smoked, was a current smoker, was a former smoker, had a confidante, and had a spouse. Work status ( 1 = full-time, $0=$ part-time) and the woman's socioeconomic status ( $1=$ advanced or graduate degree, $0=$ registered nurse or bachelor's degree) were rescored to indicate status. Age, body mass index (weight in kilograms divided by squared height in meters), alcohol intake (grams of ethanol per day), and recreational exercise (average amount of time per week over the last year a person engaged in 7 common activities: jogging, running, lap swimming, bicycling, rowing, calisthenics, and racquet sports) were all measured continuously. However, to avoid making the assumption that these variables were linearly related to health status, we categorized them according to their empirical distributions. Age was grouped into quintiles, exercise into quartiles, and body mass index into categories $(<21,23-25,25-29,>29)$ used by Willett (24). About $60 \%$ of the sample reported no alcohol consumption; the remaining $40 \%$ were grouped into 2 approximately equal categories $(1-15 \mathrm{~g}$ of ethanol per day and $>15 \mathrm{~g}$ of ethanol per day). In this cohort, the validity of alcohol intake, recreational exercise, and body weight reporting have been previously established (24-26). Finally, we included 2 additional measures of self-reported work conditions assessing physical demands ( $1=$ have a physically de- 
manding job, $0=$ does not have a physically demanding job), and job security $(1=$ does not have job security, $0=$ has job security) (16).

\section{Data analysis}

The first phase of analysis examined the crude (ie, unadjusted) means for each health status measure. To determine whether the nurses' means differed from those of a comparably aged sample of the general female population of the United States, the z-test was used (27). Next, with the focus solely on the nurses' sample, the mean health status scores were compared across the 4 job-strain groups. One-way random effects analysis of variance (ANOVA) (SAS PROC GLM) was used to compare the group means for normally distributed health status measures (physical functioning, pain, vitality, mental health). For the 2 role limitation measures, which had skewed distributions, the nonparametric KruskalWallis test (SAS PROC NPARIWAY) was used instead (27).

The distribution of the other health and life-style variables (eg, chronic conditions, smoking, marital status, etc) were also compared across the job strain categories. Age-adjusted means (using a direct standardization method) were computed for the total sample and each job strain category (28). Percentages were calculated for dichotomous variables.

Four multiple linear regression models (using SAS PROC REG) were developed for the following dependent variables measured on a continuous scale and normally distributed: physical functioning, vitality, freedom from pain, and mental health. Eight models were estimated -4 with job strain as the primary exposure and 4 with iso-strain as the primary exposure. All of these models also controlled for the potential confounding factors of co-morbid conditions, body mass index, smoking status, physical activity, alcohol intake, full-time or part-time, marital status, confidante, nurses' education, job insecurity, and physical demands of the work.

The regression coefficients and $95 \%$ confidence intervals of the main psychosocial work variables are presented. The regression coefficients can be interpreted as the average dif- ference in health status scores compared with the reference group when controlled for potential confounders (29). The regression intercept value represents the average score for the reference group (active work in the job strain models and high social support and active work in the iso-strain models).

Multiple logistic regression models were similarly fitted (using SAS PROC LOGISTIC) for both of the role limitation scales. Logistic models were necessary because the role limitation measures were recoded to $0 / 1$ due to the extreme skewness. A parallel set of 8 logistic models was developed with exactly the same set of independent variables as the linear models. The regression coefficients were exponentiated (base e) so they could be interpreted as odds ratios (active as the comparison group in the job strain models and high social support and active in the iso-strain models). The odds ratios and 95\% confidence intervals are reported for all the work-related variables (30).

We verified the model fit of the linear regression models by examining the distribution of studentized residuals across different levels of job strain (29). We verified the fit of the logistic regression models with the Hosmer-Lemeshow goodness-of-fit test (30). In all cases, the models fit well.

\section{Results}

\section{Characteristics of the sample and the distribution of covariates}

Table 1 shows the age-standardized distribution of the healthstatus scale scores for the total sample, work exposure categories, and American norms. Compared with norms for employed women in the United States for the SF-36 (17), the levels of physical functioning and freedom from pain were significantly higher for employed women in the nurses' health study; this result possibly reflects a healthy worker effect. The American norms also included women with any preexisting major illness which contributed to the lower health status scale scores. Women in the nurses' cohort who engaged in high-strain work had the lowest mean scores for

Table 1. Distribution of the mean health status scores by job strain groups and in comparison with US norms for working women between the ages of $45-72$ years. (US = United States, NHS = nurses' health study)

\begin{tabular}{|c|c|c|c|c|c|c|}
\hline & \multicolumn{6}{|c|}{ Job-strain groupa } \\
\hline & $\begin{array}{c}\text { Female US } \\
\text { norm } \\
(N=234)\end{array}$ & $\begin{array}{c}\text { Total NHS } \\
\text { sample } \\
(\mathrm{N}=33689)\end{array}$ & $\begin{array}{c}\text { Low } \\
\text { strain } \\
(N=7241)\end{array}$ & $\begin{array}{c}\text { High } \\
\text { strain } \\
(\mathrm{N}=8091)\end{array}$ & $\begin{array}{c}\text { Active } \\
(\mathrm{N}=7793)\end{array}$ & $\begin{array}{c}\text { Passive } \\
(\mathbb{N}=10564)\end{array}$ \\
\hline Physical functioning & 82.0 & 89.0 & 89.7 & 88.3 & 90.4 & 88.2 \\
\hline Vitality & 61.8 & 63.6 & 68.1 & 58.9 & 64.3 & 63.5 \\
\hline Pain (freedom from) & 72.0 & 76.0 & 78.5 & 72.9 & 76.8 & 76.1 \\
\hline Mental health & 75.9 & 76.1 & 80.0 & 72.0 & 76.2 & 76.5 \\
\hline Role-emotional & 84.5 & 84.2 & 87.3 & 78.6 & 84.2 & 85.1 \\
\hline Role-physical & 83.2 & 80.5 & 84.7 & 75.1 & 82.9 & 80.0 \\
\hline
\end{tabular}

a Differences among the job-strain groups (NHS) tested with 1 -way, random effects analysis of variance (rows $1-4$, P $<.001$ for all 4 rows) and Kruskal-Wallis test (rows $5-6, P<.001$ for both rows). Differences between normative data and NHS sample tested with 2 sample $z$-test of means (P<.001 for rows 1 and $3, P>.05$ for all other rows). US normative data based on a reanalysis of data appearing in the SF-36 Health Survey Manual and Interpretation Guide (17). 
Table 2. Age-standardized distribution of covariates by job strain exposure group ( $N=33689$ ). (MET = multiples of basal metabolic rate, $\mathrm{RN}=$ registered nurse, $\mathrm{BA}=$ bachelor of arts, $\mathrm{NHS}=$ nurses' health study)

\begin{tabular}{|c|c|c|c|c|c|}
\hline & $\begin{array}{c}\text { Total } \\
(\mathbf{N}=33689)\end{array}$ & $\begin{array}{l}\text { Low strain } \\
(N=7241)\end{array}$ & $\begin{array}{l}\text { High strain } \\
(\mathrm{N}=8091)\end{array}$ & $\begin{array}{c}\text { Active } \\
(\mathrm{N}=7793)\end{array}$ & $\begin{array}{c}\text { Passive } \\
(\mathrm{N}=10564)\end{array}$ \\
\hline \multicolumn{6}{|l|}{ Standardized means ${ }^{\hat{a}}$} \\
\hline $\begin{array}{l}\text { Alcohol (g/day in } 1990) \\
\text { Body mass index }\left(\mathrm{kg} / \mathrm{m}^{2}\right) \\
\text { Recreational exercise (MET hours/week) }\end{array}$ & $\begin{array}{l}13.8 \\
26.1 \\
17.4\end{array}$ & $\begin{array}{l}14.8 \\
26.4 \\
18.1\end{array}$ & $\begin{array}{l}12.0 \\
25.9 \\
16.6\end{array}$ & $\begin{array}{l}13.7 \\
25.9 \\
18.6\end{array}$ & $\begin{array}{l}14.1 \\
26.1 \\
16.6\end{array}$ \\
\hline \multicolumn{6}{|l|}{ Standardized percents ${ }^{a}$} \\
\hline $\begin{array}{l}\text { Part-time worker }(\%) \\
\text { Current smoker (\%) } \\
\text { Past smoker (\%) } \\
\text { Diabetic (\%) } \\
\text { High cholesterol }(\%) \\
\text { High blood pressure }(\%) \\
\text { Arthritis }(\%) \\
\text { RN/BS degree (\%) } \\
\text { Married (\%) } \\
\text { Confidante present (\%) } \\
\text { Agree have good job security }(\%) \\
\text { Agree job requires physical effort }(\%)\end{array}$ & $\begin{array}{r}43.7 \\
14.0 \\
40.8 \\
4.1 \\
35.1 \\
29.3 \\
35.8 \\
87.3 \\
77.7 \\
93.8 \\
83.0 \\
38.4\end{array}$ & $\begin{array}{r}36.6 \\
13.3 \\
41.4 \\
4.1 \\
35.1 \\
29.3 \\
33.9 \\
79.2 \\
77.6 \\
95.8 \\
88.2 \\
22.9\end{array}$ & $\begin{array}{r}45.3 \\
14.7 \\
40.5 \\
4.0 \\
35.6 \\
29.8 \\
37.6 \\
93.1 \\
77.1 \\
92.5 \\
77.8 \\
63.6\end{array}$ & $\begin{array}{r}24.5 \\
15.2 \\
38.8 \\
4.3 \\
34.4 \\
28.0 \\
34.6 \\
79.8 \\
77.6 \\
93.8 \\
86.2 \\
53.9\end{array}$ & $\begin{array}{r}57.0 \\
13.2 \\
41.2 \\
4.3 \\
35.0 \\
29.8 \\
36.1 \\
92.9 \\
78.8 \\
93.4 \\
81.4 \\
24.6\end{array}$ \\
\hline
\end{tabular}

a Standardized to the age distribution of the entire NHS cohort, using the direct method.

5 health status scales and a level of physical functioning similar to women in passive work. Table 2 shows the agestandardized distribution of the covariates for the total sample and across the job strain categories. Modest differences were noted in the socioeconomic status of the women, especially high-strain work compared with low-strain work, the former being less likely to hold graduate degrees (beyond registered nurse or bachelor's degree). Overall, women in the cohort reported high job security (83.0\%); however, the women in high-strain work were the least likely to agree that they had good job security (77.8\%). Part-time workers were the least likely to be engaged in active work and the most likely to be engaged in passive work. No major differences were apparent in the distribution of health behavior across categories of psychosocial work-environment exposure. However, women in high-strain work were the most likely to agree that their work required physical exertion; they also had the highest prevalence of self-reported arthritis.

\section{Job strain, iso-strain, functional health status and well-being}

Compared with active work, high-strain work was associated with a modest, but statistically significant, reduction in physical functioning (1.0 point decrement) (table 3 ). High-strain work was also associated with a 4.4-point reduction in vitality, a 3.3-point reduction in mental health, and a 2.4-point reduction in bodily pain (indicating higher levels of pain). By contrast, women in low-strain work showed the highest levels of mental health, vitality, and freedom from pain when compared with any other group.

Data for iso-strain are shown in the lower half of table 3. The data consistently indicate that iso-strain work (heavy demands, low control, and low support) was associated with the lowest levels of health status. The effects of iso-strain were the most pronounced for vitality [7.0-point reduction,
$95 \%$ confidence interval ( $95 \%$ CI) $6.2-7.8$ ] and mental health (5.6-point reduction, 95\% CI 5.0-6.2). A difference of 5 points or more in the SF-36 scores is regarded as clinically and socially significant (17).

\section{Job strain, iso-strain and role limitations}

Table 4 presents the logistic regression models for role limitations due to physical and emotional problems. After multivariate adjustment, the women in high-strain work were more likely to report role limitations due to physical problems [odds ratio (OR) $1.42,95 \% \mathrm{CI} 1.32-1.52$ ], as well as emotional problems (OR 1.34, 96\% CI 1.25-1.44). The effects on role limitations of working in high-strain work was comparable in magnitude to the effects of having rheumatoid or osteoarthritis (data not shown). Compared with women in active work, women in low-strain work were at lower risk of being limited due to physical problems (OR 0.82, 95\% CI $0.76-0.88$ ) and emotional problems (OR $0.63,95 \% \mathrm{CI}$ $0.58-0.68)$. Women in iso-strain work were at even higher risk of role limitations (bottom half of table 4). Conversely, working in low strain or socially supportive work environments was associated with the lowest risks.

\section{Discussion}

With the use of the Karasek job strain exposure measure (16), the psychosocial work environment has been shown to be an important determinant of health status among working women in the United States. Both job strain and iso-strain were predictive of poorer health in the 6 dimensions of health status examined. A more pervasive effect of job strain on the SF-36 scales was found as compared with another similar study (14). While the job strain framework suggests active 
Table 3. Linear regression of health status on work organization..$^{\mathrm{a}, \mathrm{b}}$

\begin{tabular}{|c|c|c|c|c|c|c|c|c|}
\hline & \multicolumn{2}{|c|}{ Physical function } & \multicolumn{2}{|c|}{ Pain (freedom from) } & \multicolumn{2}{|c|}{ Vitality } & \multicolumn{2}{|c|}{ Mental health } \\
\hline & $\begin{array}{l}\text { Regression } \\
\text { coefficient }\end{array}$ & $\begin{array}{l}\text { Standard } \\
\text { error }\end{array}$ & $\begin{array}{l}\text { Regression } \\
\text { coefficient }\end{array}$ & $\begin{array}{l}\text { Standard } \\
\text { error }\end{array}$ & $\begin{array}{l}\text { Regression } \\
\text { coefficient }\end{array}$ & $\begin{array}{l}\text { Standard } \\
\text { error }\end{array}$ & $\begin{array}{l}\text { Regression } \\
\text { coefficient }\end{array}$ & $\begin{array}{l}\text { Standard } \\
\text { error }\end{array}$ \\
\hline \multicolumn{9}{|l|}{$\begin{array}{l}\text { Model 1: job strain } \\
(N=33689)\end{array}$} \\
\hline $\begin{array}{l}\text { Intercept } \\
\text { High strain } \\
\text { Low strain } \\
\text { Passive } \\
\text { Job insecurity } \\
\text { Physical effort } \\
\mathrm{R}^{2} \text { adj } \\
\text { F-test }\end{array}$ & $\begin{array}{l}91.2^{* \star *} \\
-1.0^{* \star *} \\
-0.2^{-2} \\
-0.5^{\star} \\
-0.9^{\star \star *} \\
0.6^{\star \star \star} \\
17.8^{\%} \\
229.3^{\star \star *}\end{array}$ & $\begin{array}{l}0.6 \\
0.2 \\
0.2 \\
0.2 \\
0.1 \\
0.2\end{array}$ & $\begin{array}{l}80.1^{* * *} \\
-2.4^{* * *} \\
1.5^{* * *} \\
0.2^{* * *} \\
-1.4^{* * *} \\
-0.7^{* * *} \\
14.6 \% \\
181.4^{* * *}\end{array}$ & $\begin{array}{l}0.8 \\
0.3 \\
0.3 \\
0.3 \\
0.1 \\
0.2\end{array}$ & $\begin{array}{l}57.7^{* * *} \\
-4.4^{* \star *} \\
3.2^{* \star *} \\
-0.6^{\star} \\
-2.3^{* * *} \\
0.8^{* \star *} \\
15.6 \% \\
194.8^{* * *}\end{array}$ & $\begin{array}{l}0.7 \\
0.3 \\
0.3 \\
0.3 \\
0.1 \\
0.2\end{array}$ & $\begin{array}{c}72.5^{* * *} \\
-3.3^{* * *} \\
3.4^{* * *} \\
0.5^{\star} \\
-2.7^{* * *} \\
0.5^{\star \star *} \\
10.4 \% \\
123.1^{* \star *}\end{array}$ & $\begin{array}{l}0.6 \\
0.2 \\
0.2 \\
0.2 \\
0.1 \\
0.2\end{array}$ \\
\hline \multicolumn{9}{|l|}{$\begin{array}{l}\text { Model 2: iso-strain } \\
(N=28489)\end{array}$} \\
\hline $\begin{array}{l}\text { Intercept } \\
\text { Iso-strain } \\
\text { High strain/high support } \\
\text { Low strain/low support } \\
\text { Low strain/high support } \\
\text { Passive/low support } \\
\text { Passive/high support } \\
\text { Active/low support } \\
\text { Job insecurity } \\
\text { Physical effort } \\
\text { Re }^{2} \text { adj } \\
\text { F-test }\end{array}$ & $\begin{array}{l}91.4^{* * *} \\
-1.1^{* \star *} \\
-0.9^{*} \\
-0.5 \\
0.1 \\
-0.7^{\star} \\
-0.6 \\
-0.1 \\
-1.0^{* \star *} \\
0.6^{* * *} \\
17.7^{*} \\
171.6^{* *}\end{array}$ & $\begin{array}{l}0.7 \\
0.3 \\
0.5 \\
0.4 \\
0.4 \\
0.3 \\
0.4 \\
0.3 \\
0.1 \\
0.2\end{array}$ & $\begin{array}{l}80.7^{* * *} \\
-3.6^{* * *} \\
-2.1^{* *} \\
0.5^{*} \\
1.1^{*} \\
-0.6 \\
-0.9^{* *} \\
-1.4^{* *} \\
-1.3^{* * *} \\
-0.8^{* *} \\
14.7^{*} \\
136.9^{* * *}\end{array}$ & $\begin{array}{l}0.9 \\
0.4 \\
0.6 \\
0.5 \\
0.5 \\
0.4 \\
0.5 \\
0.4 \\
0.2 \\
0.2\end{array}$ & 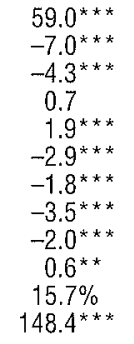 & $\begin{array}{l}0.8 \\
0.4 \\
0.6 \\
0.4 \\
0.4 \\
0.4 \\
0.5 \\
0.4 \\
0.1 \\
0.2\end{array}$ & 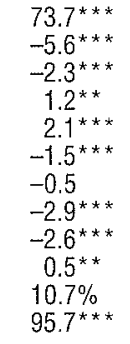 & $\begin{array}{l}0.6 \\
0.3 \\
0.5 \\
0.4 \\
0.4 \\
0.3 \\
0.4 \\
0.3 \\
0.1 \\
0.2\end{array}$ \\
\hline
\end{tabular}

a All models control for part/full-time work status, age, body mass index, exercise, smoking, diabetes, arthritis, hypertension, high cholesterol, alcohol, nurse's education, currently married, presence of a confidante.

b Regression coefficients with (standard errors).

${ }^{*} 0.01<\mathrm{P}<0.05,{ }^{* *} 0.001<\mathrm{P}<0.01,{ }^{* * *} \mathrm{P}<0.001$.

work should be associated with the best health status, lowstrain work was associated with better functioning. Both low strain and active work share high levels of decision latitude, suggesting that higher levels of control may be particularly important in promoting health (31). In the only other study of job strain using the same outcome measure (14), the authors did not detect a significant job security effect on health status. A sense of security was protective in this analysis. This difference may be due in part to growing labor market instability in the health care field in 1992, when this survey was conducted, as compared with 1990, when the earlier study (14) was conducted. However, the cross-sectional design of both studies limits causal interpretations.

To our knowledge, this is the first study to examine the association of iso-strain work with the health status of working women in the United States. Iso-strain work was associated with the poorest health status and the greatest risks of role limitations. Whereas Johnson \& Hall's study of Swedish women (3) found only an increased risk for blue-collar jobs, these results point to the hazards within service sector jobs. Studies of employed men found that iso-strain work was associated with higher age-specific cardiovascular morbidity and mortality rates (4) and an increased risk for hypertension (6). Previous studies of job strain in women did not have exposure information on work-related social support $(7,8,32-38)$, examined only 2 -way interactions (11) or only main effects $(13,39-42)$ or did not disaggregate the data by gender $(7,14,43)$. These findings suggest that
Table 4. Logistic regression of role limitations on work organization. ${ }^{2}$ ( $95 \% \mathrm{Cl}=95 \%$ confidence interval)

\begin{tabular}{|c|c|c|}
\hline & motional & Role-physical \\
\hline $\begin{array}{l}\text { Odds } \\
\text { ratio }\end{array}$ & $95 \% \mathrm{Cl}$ & $\begin{array}{l}\text { Odds } \\
\text { ratio }\end{array}$ \\
\hline
\end{tabular}

Model 1: job strain

$(\mathrm{N}=33689$

$\begin{array}{lllll}\text { High strain } & 1.34 & 1.25-1.43 & 1.42 & 1.32-1.52 \\ \text { Low strain } & 0.63 & 0.58-0.68 & 0.81 & 0.75-0.88 \\ \text { Passive } & 0.89 & 0.83-0.95 & 1.04 & 0.97-1.11 \\ \text { Job insecurity } & 1.37 & 1.33-1.42 & 1.24 & 1.20-1.29 \\ \text { Physical effort } & 0.97 & 0.92-1.02 & 1.08 & 1.03-1.14 \\ \text { Model 2: iso-strain } & & & & \\ \text { N = 28 489) } & & & & \\ \text { Iso-strain } & 1.69 & 1.53-1.88 & 1.64 & 1.48-1.81 \\ \text { High strain/high support } & 1.19 & 1.02-1.38 & 1.35 & 1.17-1.56 \\ \text { Low strain/low support } & 0.77 & 0.68-0.88 & 0.92 & 0.82-1.04 \\ \text { Low strain/high support } & 0.68 & 0.60-0.77 & 0.85 & 0.75-0.96 \\ \text { Passive/low support } & 1.08 & 0.97-1.20 & 1.18 & 1.07-1.31 \\ \text { Passive/high support } & 1.00 & 0.87-1.14 & 1.15 & 1.01-1.31 \\ \text { Active/low support } & 1.39 & 1.24-1.55 & 1.18 & 1.06-1.32 \\ \text { Job insecurity } & 1.35 & 1.30-1.40 & 1.23 & 1.18-1.27 \\ \text { Physical effort } & 0.95 & 0.90-1.00 & 1.10 & 1.04-1.16\end{array}$

a Models control for part/full-time work status, age, body mass index, exercise, smoking, diabetes, arthritis, hypertension, high cholesterol, alcohol, nurse's education, currently married, presence of a confidante.

incorporating social conditions at work into the measurement of psychosocial work-environment exposure improves the identification of high-risk work arrangements.

There were several limitations to this study. Data were not available on past work organization exposure. Current 
exposure status may not necessarily reflect past exposure in this cohort of middle-aged and older women. Moreover, a selection bias could have arisen if women changed nursing jobs due to their health status. As a partial correction for this possibility, women with major disease conditions that might influence job shifts were excluded from the analysis. Future studies should incorporate life-course exposure models and compare the job strain and iso-strain models with other psychosocial work-environment exposure models.

The potential limits of self-reported exposure data have been extensively discussed elsewhere (44). Other job strain research among nurses found that variance in self-reported work load was explained by objective indicators of work load (eg, patient load and patient contact) (45). The stability of self-report work assessments over time in the Cornell work and health study lends support to the utility of the job content questionnaire in epidemiologic research; for job decision latitude the correlation between assessments taken 3 years apart is 0.62 and for job demands it is 0.61 (Joseph Schwartz, personal communication). These values are comparable with the 0.73 correlation obtained in the same study for ambulatory blood pressure.

The generalizability of the results was assessed by comparing the nurses' health study respondent mean SF-36 scale scores to national norms for the SF-36 (17). Overall, the employed participants in the nurses' health study were comparable with working women in the United States for each of the 6 health status scales (table 1). The respondents in the nurses' health study reported higher levels of physical functioning and freedom from pain, a finding reflecting some selection of women out of an often physically demanding occupation (46). Overall, the data from the nurses' health study (SF-36) are reasonably generalizable to the general population of working women.

Our findings, along with those of other studies of health care professionals $(13,47)$, particularly nurses $(41,45,48)$, suggest that those who are restructuring the health care sector should consider the potential health hazards of certain psychosocial work environments, as well as the opportunities for health improvements presented by alternative work arrangements.

\section{Acknowledgments}

This research was funded by a grant from the National Institute of Aging Research (RO1-AG-12806). The nurses' health study is funded by a grant from the National Institutes of Health (NIH) (RO1-CA-40356). Dr Kawachi was supported by the NIH Career Development Award (HL03453).

The authors wish to thank William Rogers for reviewing the manuscript, Mark Kosinski for reanalyzing the SF-36 normative data, and Constance Kelley for assisting with the preparation of the article. We also wish to thank the mem- bers of the nurses' health study for their continuing participation and support.

\section{References}

1. Karasek RA Jr. Job demands, job decision latitude, and mental strain: implications for job redesign. Adm Sci Q 1979;24:285-308.

2. Karasek RA Jr, Theorell T. Healthy work: stress productivity, and the reconstruction of working life. New York (NY): Basic Books, Inc, 1990.

3. Johnson JV, Hall EM. Job strain, work place social support, and cardiovascular disease: a cross-sectional study of a random sample of the Swedish working population. Am J Public Health 1988; 78(10): $1336 \quad 42$

4. Johnson JV, Hall EM, Theorell T. Combined effects of job strain and social isolation on cardiovascular disease morbidity and mortality in a random sample of the Swedish male working population. Scand J Work Environ Health 1989;15:271-9.

5. Johnson JV. Collective control: strategies for survival in the workplace. Intl J Health Serv 1989;19(3):469-80.

6. Landsbergis PA, Schnall PL, Warren K, Pickering TG, Schwartz JE. Association between ambulatory blood pressure and alternative formulations of job strain. Scand J Work Environ Health 1994;20: 349-63.

7. Bourbonnais R, Brisson C, Moisan J, Vézina M. Job strain and psychological distress in white-collar workers. Scand J Work Environ Health 1996;22:139-45.

8. Hall EM. Double exposure: the combined impact of the home and work environments on psychosomatic strain in Swedish women and men. Int J Health Serv 1992;22(2):239—60.

9. LaCroix AZ. Occupational exposure to high demand/low control work and coronary heart disease incidence in the Framingham cohort. Chapel Hill (NC): The University of North Carolina, 1984.

10. Alfredsson L, Spetz CL, Theorell T. Type of occupation and nearfuture hospitalization for myocardial infarction and some other diagnoses. Int J Epidemiol 1985;14(3):378—88.

11. Chapman A, Mandryk JA, Frommer MS, Edye BV, Ferguson DA Chronic perceived work stress and blood pressure among Australian government employees. Scand J Work Environ Health 1990;16: $258-69$.

12. Landsbergis PA, Schnall PL, Schwart, JE, Warren, K, Pickering, TG Job strain, hypertension, and cardiovascular disease. In: Sauter SL, Murphy LR, editors. Organizational risk factors for job stress. Washington (DC): American Psychological Association, 1995:97-112.

13. Landsbergis PA. Occupational stress among health care workers: a test of the job demands-control model. J Organ Behav 1988;9:21739.

14. Letner DJ, Levine S, Malspeis S, D'Agostino RB. Job strain and health-related quality of life in a national sample. Am J Public Health 1994;84(10): $1580-5$.

15. Colditz GA. The nurses' health study: a cohort of US women followed since 1976. J Am Med Wom Assoc 1995;50:40-63.

16. Karasek RA Jr. Job content questionnaire and user's guide. Lowell (MA): Department of Work Environment, University of Massachusetts-Lowell, 1985.

17. Ware JE Jr, Snow KK, Kosinski M, Gandek B. SF-36 health survey: manual and interpretation guide. Boston (MA): New England Medical Center, The Health Institute, 1993.

18. Ware JE Jr, Sherbourne CD. The MOS 36-item short form health survey (SF-36). Med Care 1992;30(6):473-83.

19. Hays RD, Stewart AL. The structure of self-reported health in chronic disease patients. Psychol Assess 1990;2(1):22-30. 
20. McHorney CA, Ware JE Jr, Raczek AE. The MOS 36-item short form health survey (SF-36): II. psychometric and clinical tests of validity in measuring physical and mental health constructs. Med Care 1993;31(3):247-63.

21. Ware JE Jr, Davies-Avery A, Brook RH. Analysis of relationships among health status measures. Santa Monica (CA): Rand Corporation, 1980. R-1987/6-HEW.

22. McHorney CA, Kosinski M, Ware JE Jr. Comparisons of the costs and quality of norms for the SF-36 health survey collected by mail versus telephone interview: results from a national survey. Med Care 1994;32(6):551-67.

23. Ware JE Jr, Kosinski M, Keller SD. SF-36 physical and mental health summary scales: a user's manual. New York (NY): Basic Books, Inc, 1994.

24. Willett WC, Manson JE, Stampfer MJ, Colditz, GA, Rosner B, Speizer FE, et al. Weight, weight change, and coronary heart disease in women. JAMA 1995;273(6):461-5.

25. Giovannucci E, Colditz GA, Stampfer MJ, Rimm EB, Litin L, Sampson $\mathrm{L}$, et al. The assessment of alcohol consumption by a simple self-administered questionnaire. Am J Epidemiol 1991;133:810 7.

26. Wolf AM, Hunter DJ, Colditz GA, Manson JE, Stampfer MJ, Corsano KA. Reproducibility and validity of a self-administered physical activity questionnaire. Int J Epidemiol 1994;23(5):991—9.

27. Ott L. Introduction to statistical methods and data analysis. Boston (MA): Duxbury Press, 1977.

28. Rothman KJ. Modern epidemiology. Boston (MA): Little Brown and Company, 1986.

29. Kleinbaum DG, Kupper LL, Muller KE. Applied regression analysis and other multivariable methods. 2nd edition. Boston (MA): PWSKENT Publishing Co, 1988.

30. Hosmer DW, Lemeshow S. Applied logistic regression. New York (NY): John Wiley \& Sons, 1989.

31. Johnson JV, Stewart W, Hall EM, Fredlund P, Theorell T. Long-term psychosocial work environment and cardiovascular mortality among Swedish men. Am J Public Health 1996;86:324-31.

32. Braun $\mathrm{S}$, Hollander RB. Work and depression among women in the Federal Republic of Germany. Women Health 1988;14:3-26.

33. Haan MN. Job strain and ischaemic heart disease: an epidemiologic study of metal workers. Ann Clin Res 1988;20:143-5.

34. Theorell T, Perski A, Åkerstedt T, Sigala F, Ahlberg-Hultén G, Svensson J, et al. Changes in job strain in relation to changes in physiological state: a longitudinal study. Scand J Work Environ Health 1988;14:189-96.

35. Homer CJ, James SA, Siegel E. Work-related psychosocial stress and risk of preterm, low birthweight delivery. Am J Public Health 1990;135:173-7.

36. Brandt, LP, Nielsen, CV. Job stress and adverse outcome of pregnancy: a causal link or recall bias?. Am J Epidemiol 1992;135(3):30211.

37. Ceron-Mireles P, Harlow SD, Sanchez-Carillo CI. The risk of prematurity and small-for-gestational-age birth in Mexico City: the effects of working conditions and antenatal leave. Am J Public Health 1996;86(6):825-31.

38. Klonoff-Cohen HS, Cross JL, Pieper CF. Job stress and preeclampsia. Epidemiology 1996;7:245-9.

39. Hall EM, Johnson JV, Tsou TS. Women, occupation, and risk of cardiovascular morbidity and mortality. Philadelphia (PA): Hanley \& Belfus, Inc, 1993:709-19. Occupational medicine: state of the art reviews, vol 8(4).

40. Muntaner C, Anthony JC, Crum RM, Eaton WW. Psychosocial dimensions of work and the risk of drug dependence among adults. Am J Epidemiol 1995;142:1176-83.

41. Fenster L, Schaefer C, Mathur A, Hiatt RA, Pieper C, Hubbard AE, et al. Psychologic stress in the workplace and spontaneous abortion. Am J Epidemiol 1995;142:1176-83.

42. Ahlberg-Hultén GK, Theorell T, Sigala F. Social support, job strain and musculoskeletal pain among female health care personnel. Scand J Work Environ Health 1995;21:435-9.

43. Carayon P. A longitudinal test of Karasek's job strain model among office workers. Work Stress 1993;7:299_304.

44. Kasl S, Amick BC. Work stress. In: McDonald C, editor. Epidemiology of work related diseases. London: BMJ Publishing Group, 1995:239-66.

45. Fox ML, Dwyer DJ, Ganster DC. Effects of stressful job demands and control on psychological and attitudinal outcomes in a hospital setting. Acad Manage J 1993;36(2):289-318.

46. Ostlin P. Negative health selection into physically light occupations. J Epidemiol Community Health 1988;42:152-6.

47. Theorell T, Ahlberg-Hultén G, Jodko M, Sigala F, de la Torre B. Influence of job strain and emotion on blood pressure in female hospital personnel during workhours. Scand J Work Environ Health 1993;19:313-8.

48. Landerweed JA, Boumans NPG. The effect of work dimensions and need for autonomy on nurses' work satisfaction and health. J Occup Organ Psychol 1994;67:207-17.

Received for publication: 16 December 1996 